\title{
EL VIZCONDE DE EZA, ADALID DEL CONSERVADURISMO CATÓLICO EN EL PRIMER TERCIO DEL SIGLO XX
}

\author{
THE VISCOUNT OF EZA, THE CHAMPION OF CATHOLIC \\ CONSERVATISM IN THE FIRST THIRD OF THE 20th CENTURY \\ Tomás Martínez Vara, José Luis Ramos Gorostiza* \\ Universidad Complutense de Madrid. España
}

\begin{abstract}
RESUMEN: El Vizconde de Eza fue un distinguido político de la Restauración y también sobresalió como agrarista y reformador social. Pero, sobre todo, fue el principal adalid del conservadurismo católico español en el primer tercio del siglo xx. Por un lado, desarrolló una ingente y prolongada labor como publicista y divulgador de sus principios ideológicos, con una presencia constante en todos los medios de difusión de la época. Como ejemplo relevante de esta labor destaca especialmente su campaña a favor de los consorcios industriales, dentro de la corriente del nacionalismo económico. Por otro lado, intentó poner en práctica dichos principios desde las distintas instancias de poder que ocupó, incluso en ámbitos tan específicos como el del conocimiento científico: así, por ejemplo, fue responsable de la reorientación «menéndez-pelayista» de la Asociación Española para el Progreso de las Ciencias, truncando lo que podría haber sido un buen apoyo para el desarrollo científico español, y anticipando en cierto modo lo que luego sería la política científica del primer franquismo.
\end{abstract}

PALABRAS CLAVE: Vizconde de Eza, publicista, conservadurismo católico, consorcios industriales, ciencia.

ABSTRACT: The Viscount of Eza was a distinguished politician of the Restoration and also excelled as agrarian and social reformer. But, above all, he was the champion of Spanish catholic conservatism in the first third of the twentieth century. On the one hand, he developed a huge and prolonged work as a publicist and disseminator of its ideological principles, with a constant presence in all the media of the time. A relevant example of this work was his campaign in favor of industrial consortiums, within the current of economic nationalism. On the other hand, he tried to put into practice the aforementioned principles from the various positions of power that he enjoyed, even in a so specific area as scientific knowledge: in particular, he was responsible for the conservative reorientation of the Spanish Association for the Progress of Science, truncating what could have been a good support for Spanish scientific development, and anticipating in a certain way the scientific policy of the first Francoism.

KEYWORDS: Viscount of Eza, publicist, catholic conservatism, industrial consortiums, science.

* Correspondencia a: José Luis Ramos Gorostiza. Universidad Complutense de Madrid, Departamento de Economía Aplicada, Estructura e Historia, Facultad Ciencias Económicas y Empresariales, Campus de Somosaguas, 28223-Pozuelo de Alarcón, Madrid (Spain). - ramos@ccee.ucm.es - https://orcid.org/0000-0002-1187-1464

Cómo citar: Martínez Vara, Tomás; Ramos Gorostiza, José Luis (2020). «El Vizconde de Eza, adalid del conservadurismo católico en el primer tercio del siglo XX»; Historia Contemporánea, 63, 631-661. (https://doi.org/10.1387/hc.20302).

Recibido: 22 octubre, 2018; aceptado: 13 febrero, 2019.

ISSN 1130-2402 - eISSN 2340-0277 / (C) 2020 UPV/EHU

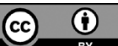

Esta obra está bajo una licencia

Creative Commons Atribución 4.0 Internacional 
Cuando en diciembre de 1945 falleció en Madrid Luis de Marichalar y Monreal, Vizconde de Eza y Marqués de Ciria, fue rememorado como un aristócrata conservador de prestigio, culto, ponderado, observador y dialogante. Aún en vida, prominentes contemporáneos suyos de diverso credo ideológico (como Gumersindo Azcárate, Adolfo G. Posada, Adolfo A. Buylla, Angel Ossorio y Gallardo, Eduardo Sanz y Escartín, Pedro Sangro y Ros de Olano, Armando Castroviejo, Severino Aznar o Luis Araujo-Costa) reconocieron su «excepcional competencia», «insaciable curiosidad» y «enorme erudición», considerándole uno de los representantes más acreditados del conservadurismo liberal y un firme baluarte de la reforma social católica, en la línea de la Rerum Novarum de León XIII. Asimismo, destacaron su papel como mecenas y como observador e intérprete de diversos acontecimientos de la esfera internacional, que conocía de primera mano gracias a su dominio de idiomas y sus frecuentes viajes $\mathrm{y}$ estancias en el extranjero.

Aunque aún no existe una monografía sobre su figura, el Vizconde ha seguido estando presente - siquiera de forma tangencial - entre los estudiosos, que se han interesado por sus amplias inquietudes intelectuales y su intensa actividad en los más diversos ámbitos de la sociedad española de su tiempo. En términos generales, Eza ha sido básicamente conceptualizado bien como un político relevante atraído por cuestiones sociológicas, económicas y morales, bien como un notable agrarista ${ }^{1}$. En términos más específicos, se han estudiado en detalle algunas de sus actuaciones concretas. Por ejemplo, en referencia a su etapa de Alcalde de Madrid, se ha analizado su sensibilidad hacia el problema de la vivienda insalubre y su actitud intervencionista en el asunto de las subsistencias básicas ${ }^{2}$; y en relación a su etapa de presidente de la Asociación Española para el Progreso de las Ciencias, se ha examinado su propuesta de concluir la historia de la filosofía española planeada por Adolfo Bonilla ${ }^{3}$. Por último, la figura de Eza también ha despertado interés como prototipo de notable - y cacique - del liberalismo conservador, que unía en su persona todas las formas de capital económico, social y político de que dispusieron las élites de la Restauración ${ }^{4}$. Así, el Vizconde fue portavoz autorizado de

\footnotetext{
${ }^{1}$ Carasa, 1997, II, pp. 361-366. Campo, 1968, Paniagua, 2019. Los trabajos más extensos (hagiográficos) son los de Calama, 2003 y 2006.

2 Huertas, 2002. Pérez Sánchez, 2005, p. 51.

${ }^{3}$ Bueno, 1992.

${ }_{4}$ Carasa, 2001. Artola, 2016, pp. 120-122.
} 
la aristocracia terrateniente, estuvo estrechamente vinculado a las grandes organizaciones agrarias del país, y coadyuvó a reforzar los tintes corporativistas que desde 1907 empapaban la vida económica española ${ }^{5}$. De hecho, formó parte del grupo de conservadores católicos, verdadera élite intelectual que leía libros de reformistas foráneos, conocía las leyes e instituciones sociales ya implantadas en Europa, e intervenía de manera activa en las controversias doctrinales y en las instancias internacionales promotoras de la reforma social ${ }^{6}$; desde dicha posición, Eza contribuyó a difundir los debates que tuvieron lugar en la Europa de entreguerras sobre lo que debía ser la constitución «orgánica y colectiva de los pueblos» ${ }^{7}$.

Este trabajo combina fuentes publicísticas y hemerográficas con otras de tipo archivístico, y se centra en dos significativos aspectos de Eza que hasta ahora no habían sido analizados con detenimiento, pero que merecen atención. En primer lugar, su intensísima labor como publicista y tenaz divulgador de los principios del conservadurismo católico, desempeñada a lo largo de toda su extensa trayectoria pública a través de prensa, revistas, conferencias, informes, panfletos, libros, etc. Esto convirtió al Vizconde en una voz identificable e influyente dentro de la compleja conformación de la opinión pública vinculada a la dispar derecha española. A modo de ejemplo concreto de dicha labor, se hará alusión al destacado papel que Eza desempeñó como propagandista de la idea de corporativización de la economía a través de la creación de consorcios industriales (idea que a su vez se inscribía dentro de la entonces pujante corriente del nacionalismo económico).

En segundo lugar, se examinará el decisivo protagonismo de Eza en el giro ideológico «menéndez-pelayista» de la Asociación Española para el Progreso de las Ciencias a partir de su XI Congreso de Cádiz (1927); dicho giro cambió radicalmente la orientación positivista inicial de la citada Asociación, y a la postre truncó lo que prometía haber sido un importante apoyo al desarrollo científico español.

Como puede apreciarse, se trata de dos facetas bien distintas del mismo personaje pero con un denominador común: Eza como verdadero adalid del conservadurismo católico del primer tercio del siglo Xx, que - por un lado - intentó propagar y divulgar en todo momento y por todos

\footnotetext{
5 Pan-Montojo, 2007b, p. 91. Velarde, 1999, p. 482.

${ }^{6}$ Montero, 2004. González Hernández (2010, p. 128) los definió con ironía como «moralistas sociales de guante blanco y chistera».

7 Perfecto 2012, p. 80.
} 
los medios de difusión a su alcance los principios políticos y socio-económicos asociados a dicha corriente ideológica; y que - por otro - , y siempre que le fue posible, intentó poner en práctica dichos principios desde las distintas instancias de poder que ocupó, incluso en ámbitos tan específicos como el del conocimiento científico.

Pero antes de abordar ambos aspectos se contextualizará la figura del Vizconde con algunos trazos biográficos básicos, haciendo especial referencia a sus mentores y a los numerosos cargos públicos que desempeñó a lo largo de su dilatada carrera política.

\section{Una intensa y prolongada actividad pública}

Luis de Marichalar y Monreal nació en Madrid en 1873, en el seno de una familia de grandes propietarios e ilustres juristas, con hondas raíces nobiliarias y larga tradición parlamentaria. Su padre y sus dos abuelos fueron juristas, parlamentarios y académicos, como luego lo sería él. A partir de 1900, ostentó el título de Vizconde de Eza, que es como se le iba a conocer desde entonces. Su matrimonio con Encarnación Bruguera, propietaria de una gran fortuna integrada por fincas, inmuebles urbanos y valores extranjeros, reafirmó su ya de por sí elevada posición, proporcionándole independencia a la hora de actuar ${ }^{8}$.

Siguiendo la tradición familiar, Eza estudió Derecho en la Universidad Central de Madrid, obteniendo a sus veintiún años el grado de doctor $^{9}$. Interesado desde muy joven por la política activa, militó en el Partido Conservador, primero bajo la protección del político madrileño Francisco Silvela («mi primer maestro») y después del gallego Eduardo Dato («maestro y amigo íntimo»). A ambos los recordaría siempre con cariño y veneración ${ }^{10}$.

8 Artola, 2016, p. 120. Por ejemplo, la declaración de la renta de Eza de 1934 («contribución general sobre la renta») da una idea de su privilegiada posición económica: ingresos anuales de más de un millón de pesetas procedentes de propiedades agrícolas, inmuebles e inversiones de capital (acciones, obligaciones, etc.). AHN, FC-Ministerio de Hacienda, 7106, Exp. 84.

9 Su tesis (inédita) fue «Notas sobre el problema social» (1892), con fuentes mayoritariamente francesas (Le Play es una de ellas). Entre los autores mencionados figuraban muy pocos españoles (Azcárate, Sanz y Escartín, Pastor Díaz o Donoso Cortés). AHN, Universidades, 4384, Exp. 1.

${ }^{10}$ Eza, 1934a, II, pp. 136-137. Eza, 1934a, I, p. 167. 
Tras el asesinato de Cánovas en 1897, Silvela se impuso a los otros líderes del Partido Conservador y consiguió formar un gobierno de concentración (1899-1900). El propio Silvela desempeñaría sucesivamente las carteras de Estado y Marina. Para Hacienda eligió a Fernández Villaverde, quien implementó con éxito una política económica basada en el rigor presupuestario, consiguiendo finalmente equilibrar las finanzas públicas, algo que luego Eza acabaría considerando un lema irrenunciable, válido en todo tiempo y lugar. De Gobernación se ocupó Dato, a quien Silvela encargó seguir en materia social las enseñanzas del pontífice León XIII contenidas en la Rerum Novarum; dio comienzo así la moderna legislación en este campo, en el que Eza empezó trabajando a las órdenes del político gallego, con el que se sentiría plenamente identificado ${ }^{11}$.

Con el fin de dotar de estabilidad al régimen, Dato abogaba por un clima de consenso con la izquierda moderada, eludiendo los métodos de fuerza y confrontación auspiciados por el maurismo ${ }^{12}$. En un texto del 6 de marzo de 1923, rememorando al político gallego tras su asesinato, Eza calificaría dicha propuesta doctrinal de honda y perdurable; una «sana revolución» conducente «no a destruir al de arriba, sino a realzar y enaltecer al de abajo», promoviendo así «la concordia interclasista» que permitiría mantener el statu quo ${ }^{13}$. Eza destacaba asimismo otras tres virtudes de Dato: su insistencia en el fortalecimiento del individuo frente al Estado, entendiendo éste como un «mal necesario» al que sólo correspondía la función «supletoria de las fuerzas sociales escasas» ${ }^{14}$; su constante preocupación «por todo aquello que condujera a una verdadera y legítima ordenación social»; y la necesidad de capacitar a una «élite» que se encargara de guiar y, sobre todo, educar a la masa social, haciéndola comprender que, frente a la «errónea exageración de los principios de soberanía popular», estaba el deber cristiano de aceptar el cometido social asignado a cada uno en particular ${ }^{15}$.

11 Representativa de esta línea reformista sería la Ley de Accidentes de Trabajo (1900). Eza redactó la exposición del dictamen de la Comisión del Congreso. Montero, 1981, pp. 33-91. Lamentablemente no se ha podido consultar el archivo de Dato (sito en la Real Academia de la Historia), por estar en proceso de reorganización.

12 El maurismo defendía en el fondo similares postulados. Sobre su política social, González Hernández, 1987.

13 Eza, 1934a, I, pp. 3-13.

14 Eza, 1934a, I, p. 23.

15 Eza, 1934a, I, pp. 10-12, 22-24, 32-35. 
Hasta el asesinato de Dato y el advenimiento de la dictadura primorriverista, Eza desplegaría una intensa actividad política en el Partido Conservador. Fue elegido ininterrumpidamente parlamentario por el distrito de Soria entre 1899 y 1923. Aunque su vida transcurriría casi por entero en Madrid, donde disponía de bufete propio, regiría en todo momento los destinos de la política provincial soriana, en particular tras el fallecimiento del canovista y cabeza del partido conservador Ramón Benito Aceña ${ }^{16}$.

Director General de Agricultura, Industria y Comercio entre 1907 y 1908, bajo el mandato en Fomento del villaverdista Augusto González Besada (en el Gobierno largo de Maura), Eza fue artífice de la Ley de Colonización y Repoblación Interior e impulsor de la racionalización de los cultivos y el crédito agrícola ${ }^{17}$. Asimismo, entre 1908 y 1917 refundó y presidió la Asociación de Agricultores de España, haciendo de ella «un lobby de lobbies agrarios». En este sentido, la política de Eza y González Besada, en detrimento de la expansión de la esfera pública, estuvo marcada «por la aspiración a integrar y fortalecer a los grupos sociales relevantes, organizados en asociaciones, y representados en órganos de carácter público o semipúblico» ${ }^{18}$.

En 1912 el Partido Conservador se escindió entre los «mauristas» y los «idóneos» acaudillados por Dato. Eza permaneció obviamente al lado del político gallego, junto a otros prohombres conservadores como Joaquín Sánchez Toca o José Sánchez Guerra. Los «idóneos» en ningún momento pretendieron la transformación del régimen; «su interés se centró en la cuestión social, abordada desde una óptica transaccionista, y en la vía parlamentaria» ${ }^{19}$.

Entre noviembre de 1913 y julio de 1914 Eza ocupó la Alcaldía de Madrid, que atravesaba un momento difícil: «presupuestos desnivelados, corruptelas tradicionales y elementos díscolos ${ }^{20}$. La realidad socio-sanitaria de la ciudad era realmente lamentable y Eza lo sabía, pues estaba al corriente de los grandes debates sobre el estado de la salud pública de la población urbana entre higienistas y médicos sociales. Producto de su in-

16 Sobre la actuación política del Vizconde en Soria: Calvo, 1999.

17 La Ley de Colonización y Repoblación Interior (1907) perseguía la formación de patrimonios familiares en colonias que se constituirían ocupando terrenos de secano y montes públicos incultos. Sus resultados fueron más bien magros. Barciela, 2016, p. 1056.

18 Pan-Montojo, 2007, p. 91.

19 González Cuevas y Montero, 2001, p. 43.

20 La Época, 1 de noviembre de 1913. 
terés por el asunto fue la memoria que, por encargo suyo, confeccionó el entonces director del Laboratorio Municipal, César Chicote. Se trataba de una obra excelente que el propio Vizconde prologó, haciendo gala de notable erudición y realismo, pero también de cierto paternalismo arcaico ${ }^{21}$.

Posteriormente fue Ministro en dos gabinetes presididos por Dato: en 1917, fecha emblemática en la crisis global del régimen de la Restauración, ocupó la cartera de Fomento, y entre 1920 y 1921, la de Guerra ${ }^{22}$. En Fomento creó sin éxito una Caja Central de Crédito Agrícola, impulsó las primeras tablas sobre el cálculo de la renta nacional $(1916)^{23}$, y estableció el Consorcio Nacional Carbonero, que fue el exponente más nítido del modelo corporativo que ya había comenzado a abrirse paso en los años de González Besada ${ }^{24}$. Como Ministro de Guerra Eza hubo de hacer frente al desastre de Annual en 1921, del que salió muy tocado aunque finalmente no fuera señalado en el llamado expediente Picasso. Y poco después del asesinato de Dato, desencantado, se apartó ya definitivamente del primer plano de la política para el resto de su vida ${ }^{25}$. No obstante, continuaría ocupando diversos cargos públicos.

21 Huertas, 2002, p. 264. Eza, 1914.

22 Tras el asesinato de Dato, el 8 marzo 1921, Eza ocuparía cinco días la cartera de Marina en el gobierno interino de Bugallal.

${ }^{23}$ Dicha estimación para el año 1915, la primera que se hizo en España, no era sino un compendio de las confusiones en las que incurrieron los pioneros del cálculo de magnitudes agregadas (Cubel y Palafox, 1997, p. 117). Se trataba de «datos puestos a ojo de buen cubero» y de fragmentos de la sociología cristiana francesa repartidos profusamente, como diría años después Luis Olariaga en un lúcido artículo - «La investigación científica de la economía española»- aparecido en el Sol el 20 de febrero de 1918. En concreto, Olariaga se refería a las obras de Eza El problema agrario y El problema económico de España. Las buenas intenciones del Vizconde iban de la mano - según Olariaga - de su «mesiánica pretensión de arreglar el país sin haber estudiado previamente con seriedad ninguno de sus problemas»; dicha pretensión podría «serle a él [Eza] muy útil en nuestra política pintoresca, pero tenemos cierta aprensión de que no va a serle tan útil a la Economía Política».

24 Velarde, 1999, p. 482.

25 Eza no quiso participar directamente en un régimen como el Directorio militar, que suspendió la - tan apreciada por él- Constitución de 1876 (sobre dicha norma véase Eza, 1928). Según Calama (2003, p. 263), la Dictadura intentó captarle ofreciéndole la embajada de Londres. Eza también prefirió mantenerse al margen de la II República, un sistema político que no encajaba en sus principios monárquicos y tradicionalistas; de hecho, su candidatura a las elecciones de febrero de 1936 como «agrario independiente» fue meramente anecdótica. Por último, durante el primer franquismo - ya mayor, definitivamente roto el modelo del conservadurismo tradicional, y tras pasar la guerra penosamente en el Madrid republicano- se dejó querer como símbolo de la restauración de la moral católica. Son ilustrativos en este sentido sus textos sobre el modelo tradicional de mujer: De «niñas 
En el terreno social, Eza fue primero vocal - representando a la patronal - y más tarde presidente - entre 1918 y 1924 - del Instituto de Reformas Sociales (IRS). Relevó en el cargo, tras a su muerte, al krausista republicano Gumersindo Azcárate, del que fue amigo y colaborador. Dentro de dicha institución, organizó en 1919 la Sección de Cultura y Acción Social que dirigiría Leopoldo Palacios, y en la que se establecieron unas enseñanzas no formales - a base de cursillos y conferencias sobre materias económicas y sociales - que acabarían convirtiéndose en el embrión de las futuras Escuelas Sociales.

Pero además Eza formó parte de la semipública sección española de la Asociación Internacional para la Protección Legal de los Trabajadores (AIPT), matriz de la futura Organización Internacional del Trabajo (OIT). Creada en enero de 1907, la Sociedad para el Progreso de la Legislación del Trabajo, que así se conocía a la citada sección española, fue una institución paralela $-\mathrm{y}$ en cierto modo complementaria - del IRS. Funcionó como una auténtica plataforma de convergencia y colaboración de las élites reformadoras madrileñas (católicas y liberales «institucionistas»), y en su creación estuvieron implicadas las mismas personas que en ese momento trabajaban dentro del IRS para fundar el Instituto Nacional de Previsión (1908), a cuyos órganos directivos y consultivos también pertenecería Eza. Tras la muerte de Dato en 1921, el Vizconde llegaría a ser presidente de la sección española de la Asociación Internacional para el Progreso Social (AIPS), continuadora de AIPT tras la creación de la OIT, a la que España se había incorporado en 1919 y cuyos fines - en su opinión - estaban por encima de los «de los partidos» ${ }^{26}$.

Asimismo, Eza fue miembro de la Asociación para el Mejoramiento de la Clase Obrera y vocal del Consejo Superior de Protección a la Infancia, creado a propósito de la Ley General de Protección a la Infancia y Represión de la Mendicidad (1904). También tuvo una presencia constante en las

bien» a «servidoras del bien» (1940), El alma femenina española (1940), o Corazón de la madre española (1942).

26 Así lo expresó el Vizconde a Antonio Maura nada más regresar de la I Conferencia Internacional del Trabajo de la Sociedad de Naciones, celebrada en Washington en octubre-noviembre de 1919, y cuya delegación había presidido (Fundación Antonio Maura, Fondo Antonio Maura, leg. 221/6). Años después, en 1924, Eza invitó a su hijo, Gabriel Maura, a colaborar con la AIPS, pues ello no sólo aumentaría el número de socios, sino también -y esto era lo importante- «la calidad» del personal, «cuyo concurso consideramos indispensable» (Archivo de la Fundación Antonio Maura, Fondo Gabriel Maura, leg. 120/2). 
organizaciones del catolicismo social, formando parte del Consejo Nacional de Corporaciones Católico-Obreras y de la Junta Central de Congresos Católicos. Lejos de limitarse a una mera vinculación formal, se mostró muy activo en los debates que tuvieron lugar en los diferentes Congresos Católicos y Semanas Sociales respecto a cuestiones tales como el descanso dominical, el salario justo, el modelo asociativo obrero o el papel del Estado.

Por último, en el ámbito científico-académico, el Vizconde fue académico de número de la Real Academia de Jurisprudencia y Legislación y de la Real Academia de Ciencias Morales y Políticas, y también fue vocal de la Junta de Ampliación de Estudios e Investigaciones Científicas (JAE). Esta importante institución, creada en 1907, propugnaba el envío de pensionados al extranjero, y representó un gran esfuerzo modernizador y de homologación a estándares internacionales en la política científica española ${ }^{27}$. Aunque Eza no figuró inicialmente entre los veintiún vocales vitalicios de la Junta liderada por Ramón y Cajal, sí ocuparía posteriormente una de las vacantes producidas. Por otro lado, tras el fallecimiento de Rodríguez Carracido en 1927, el sino Vizconde pasó a presidir la Asociación Española para el Progreso de las Ciencias (AEPC), donde tampoco se limitó a ejercer una mera función representativa. Su labor en esta institución se abordará más adelante.

En definitiva, Eza perteneció a la élite que estaba presente en medios de comunicación y editoriales, instituciones de reforma social (IRS, INP, etc.), e instituciones científico-educativas (JAE, AEPC, Real Academia de Ciencias Morales, etc. $)^{28}$. Es decir, formó parte de la élite política y económica que compartía espacios de sociabilidad, cultura e identidad comunes, y participaba de amplias redes clientelares ${ }^{29}$.

\section{Contribuyendo a crear opinión: Eza como propagandista y divulgador de los principios del conservadurismo católico}

Pese a su intensa vida pública, la obra del Vizconde fue realmente ingente (libros, ensayos, artículos periodísticos y académicos, conferencias,

27 Otero, 2001.

28 Por ejemplo, como ha señalado Glick (1993, pp. 94-95), trece de los integrantes del INP (entre los que había social-católicos, conservadores, liberales de distinto signo e institucionistas) fueron socios de la AEPC y algunos de ellos - como Eza - también fueron vocales de la JAE. A su vez, la mayoría aparecía en una multiplicidad de instituciones de carácter reformista.

29 Pan-Montojo, 2007a, p. 12. 
discursos, participación en congresos, cursos y debates, etc.). Abarcó además cuatro grandes ámbitos temáticos - agrarismo, economía, sociología y política - y se extendió a lo largo de casi medio siglo, hasta el mismo año de su fallecimiento. Pero, como cabría esperar, no fue la obra de un pensador original, sino la obra repetitiva, asistemática y generalmente superficial de un publicista informado e intelectualmente inquieto, que intentaba estar al tanto de aquellas novedades editoriales que pudieran servirle para apuntalar mejor sus posiciones.

Es decir, se trataba de textos - dirigidos a un público «proclive» $\mathrm{y}$ educado, pero no especialista - al servicio de una única causa: la divulgación y defensa de los principios del conservadurismo católico, posición que - en lo esencial - Eza mantuvo sin cambios significativos durante toda su vida (tradicionalismo, corporativismo, elitismo, paternalismo social, etc.), aunque con los años fuera moldeándola conforme se desarrollaban los acontecimientos y acentuando un tono cada vez más reaccionario.

En casi todos sus escritos, cualquiera que fuera su naturaleza, Eza siguió una técnica de trabajo similar: estaban plagados de citas directas e indirectas, hasta el punto de ser una especie de recensiones encadenadas de aquellas obras de mayor actualidad que el Vizconde consideraba adecuadas al tema que en ese momento estuviera tratando. Es decir, atento a las novedades bibliográficas nacionales y extranjeras en los campos que le interesaban, Eza incorporaba a sus escritos las principales ideas de los últimos libros y artículos leídos (tanto en prensa como en revistas académicas) sobre aquel asunto concreto que estuviera analizando, y a partir de ahí planteaba sus propias reflexiones de síntesis, siempre en línea con los principios del conservadurismo católico. A la acumulación de citas se unía el estilo propio de quien produce textos incesantemente, sin dejarlos reposar: a menudo carentes de una estructura bien definida, con frases demasiado largas y frecuentes reiteraciones y vaguedades.

Buena parte de los libros de Eza consisten precisamente en recopilaciones de artículos ya publicados o en la ampliación y revisión de conferencias previamente pronunciadas en instituciones públicas y privadas. De hecho, las revistas y periódicos no sólo fueron su campo habitual de expresión, sino que a su vez reseñaron encomiásticamente las obras y actividades del propio Vizconde. En este doble sentido, los dos periódicos más importantes para Eza fueron el monárquico $A B C$ y el diario La Época - portavoz del Partido Conservador y defensor de la monarquía parlamentaria-, aunque también publicó en otros medios de difusión de no tan claro carácter conservador. En el ámbito de las publicaciones periódi- 
cas del catolicismo social, cabría citar: Revista Católica de Cuestiones Sociales, Revista Quincenal, La Paz Social y Revista Social. Y en el ámbito más académico, más tardíamente: Revista Internacional de Sociología, Revista Nacional de Economía, Revista de Estudios Políticos, y Economía Española.

En 1950, la Sección de Estudios de la Escuela Social de Madrid, dependiente del Ministerio de Trabajo, editó una amplísima Antología que recogía extensos extractos de los trabajos más relevantes de Eza sobre los cuatro tipos de cuestiones de actualidad por las que se interesó: agrarias, políticas, económicas y sociales. Lo significativo es que dicha antología - con su recopilación bibliográfica final de la obra del Vizconde, que era incompleta pese a ser cuantitativamente impresionante - permite hacerse una idea de la magnitud de su constante labor divulgadora. Cabría completarla con otras recopilaciones de textos «menores», como los cinco libros titulados De mis carpetas, donde se recogían artículos aparecidos entre 1923 y 1934. El hecho de que las obras de Eza fueran amplia y regularmente reseñadas en prensa y revistas especializadas es indicativo de que tenían eco y un público fiel en el ámbito conservador y social-católico.

A modo de ejemplo concreto de la frenética actividad de Eza como publicista, en el siguiente sub-apartado se expondrá el destacado papel que desempeñó en la difusión de la idea de los consorcios industriales, de la que llegó a ser uno de sus más importantes proponentes en España. Pero antes se hará un repaso de los postulados del ideario conservador y católico-social subyacente en sus escritos de temática varia, y que Eza intentó en todo momento defender y difundir de forma más o menos explícita, aunque no de un modo sistemático ni plenamente coherente.

En términos generales, el Vizconde podría definirse como monárquico, católico ferviente y notorio conservador con barnices liberales. Aunque él mismo se calificara de liberal-conservador, ante todo fue un irreductible conservador de las esencias tradicionales, que concebía las jerarquías como naturales y necesarias en tanto que fundamento del orden social querido por Dios ${ }^{30}$. El liberalismo sólo fue en su caso, a lo sumo, un adjetivo variable, o como él mismo escribió años después, una matización impuesta por Cánovas ${ }^{31}$. Precisamente, Eza creía sintonizar con Cá-

${ }^{30}$ El pensamiento de la derecha española en Rodríguez Jiménez, 2010, pp. 21-58.

31 Eza, 1928, p. 73. 
novas en lo fundamental, y valoraba que éste hubiese restaurado la monarquía dinástica con aspecto constitucional («constitución interna») de acuerdo con la tradición católica renovada y el ser español, y no aceptando, por tanto, la tesis del pacto libre entre individuos libres.

En un sentido tradicionalista, Eza interpretaba que Dios era el soporte de todo lo creado, que la libertad no representaba un derecho individual sino un don natural gratuito, y que la religión lo impregnaba todo y constituía la base última de la moralidad y la justicia. No ha de extrañar, pues, que fueran constantes sus apelaciones tanto a pensadores tradicionalistas franceses (Chateaubriand, Lammenais, De Bonald, De Maistre) y españoles (Balmes, Cortés, Menéndez Pelayo), como a filósofos neo-tomistas (en particular al español Zeferino González, a quien tuvo como maestro).

De estos autores tomó la concepción providencialista del mundo, que implicaba la supeditación de la razón a la fe; la concepción orgánica de la sociedad, como un orden jerárquico basado en la desigualdad natural e ineludible de los hombres; y, finalmente, la identificación —en la versión más perfeccionada de Menéndez Pelayo - entre el catolicismo y el ser español, o lo que es lo mismo, la pertenencia a una nación, comunidad indisoluble fruto de un largo proceso histórico. También - siguiendo la tesis balmesiana - consideró que el progreso resultaba inevitable y era inherente a la evolución de la humanidad ${ }^{32}$.

Eza asimismo tendió a autodefinirse a veces como «conservador-demócrata», que para él era un individuo perteneciente a una minoría selecta, conservador por sus ideas y principios morales (autoridad, familia, propiedad, religión, tradición), y demócrata por la defensa del bienestar del pueblo ${ }^{33}$. En consonancia con ello, mostró igualmente su admiración hacia algunos conservadores británicos como Disraeli - por su previsión del problema social - o Burke - por el componente histórico de su pensamiento ${ }^{34}-$. Eza compartía con este último su rechazo visceral de la revolución, pero no ignoraba que el cambio histórico era necesario y que la estabilidad social reque-

32 Aunque Eza consideraba un referente a Donoso Cortés, su praxis político-social se ajustó al espíritu balmesiano, abierto y ecléctico: la evolución histórica como antídoto frente a la revolución, tratando de comprenderla y aceptarla con actitud crítica pero tolerante. Gómez Díez, 2010, p. 68.

${ }^{33}$ Eza, 1944b, pp. 320-342.

${ }^{34}$ Eza (1930a, p. 166) hizo suyas las palabras de Arthur Bauman sobre Burke: «[sus escritos son hoy] la biblia política de todos los que están del lado de la ley, de la religión, de la propiedad y del orden». 
ría una buena dosis de pragmatismo, como había observado Balmes, demostrado Cánovas y corroborado Dato en el plano social.

En 1943, ya casi al final de su vida y en plenos rigores autárquicos, Eza publicó Piedras miliarias, una especie de testamento doctrinal en cinco folletos, que en realidad eran el resultado de intervenciones suyas en la Real Academia de Ciencias Morales y Políticas, presidida entonces por Antonio Goicochea. «Piedras miliarias» eran - para él- «determinados principios, fundamentos y postulados permanentes y consustanciales a la vida social sin los que ésta no [podía] sostenerse ni mucho menos progresar», con la particularidad de que las leyes divinas debían encauzar las terrenales, haciendo «al hombre sano de espíritu y, por ende, prósperas a las sociedades en sus destinos, a los que [dotaban] de un contenido y de una finalidad» ${ }^{35}$.

Dado este fundamento espiritual, en el ámbito económico-empresarial crear o administrar un negocio significaba ciertamente procurar ganar dinero; pero el patrón católico no debía olvidar nunca que su verdadero fin era la salvación, lo que implicaba el deber de fraternidad hacia sus obreros y el respeto de su dignidad. Como base económico-jurídica del orden social colocaba la propiedad privada, resultante de un ahorro legítimo (derivado bien del trabajo o bien del interés debido al servicio prestado por el capital en contraprestación por el riesgo); pero sin obviar nunca las obligaciones sociales a las que el propietario había de responder necesariamente ${ }^{36}$.

Por otra parte, el crédito era legítimo siempre que fuera vinculado al sentido común, lo que Eza denominaba la «moralización del crédito» ${ }^{37}$. El crédito y el descuento eran operaciones fundamentales para el funcionamiento de la economía, pero su concesión requería inteligencia y buen juicio. Eza parecía así situarse del lado de algunos economistas de la época - como Hayek o Robbins - que veían el origen de muchas crisis económicas en un exceso de crédito sin suficientes garantías, que crecía con gran rapidez («inflación de crédito»). Por eso, abogaba por un crecimiento del crédito paulatino y muy controlado, siempre plenamente respaldado por el capital social líquido de las entidades bancarias, las reservas realizables y la mitad de los depósitos.

35 Eza, 1943a, p. 5.

36 Eza, 1943d, pp. 40-42. La propiedad privada nunca debía quebrantar «los estímulos irreemplazables del interés individual para la producción y para sus alimentos» (Eza, 1950, p. 77). Véase también Eza, 1934c.

37 Eza, 1943d, pp. 45-48. 
Al factor capital se añadía el trabajo, acreedor de su debida retribución $^{38}$. En las empresas privadas, el patrón compraba a la mano de obra el derecho a dirigirla («el jefe ha de ser libre de sus decisiones») a cambio del pago anticipado de una parte de los «beneficios eventuales comunes», esto es, de un salario. Este debía ser un «salario social», ajustado al coste de la vida y suficiente para asegurar una existencia digna al trabajador. El salario base sería siempre el del obrero soltero; a los trabajadores casados se les reconocerían aumentos familiares «conforme a sus condiciones de vida» - un salario familiar-, dado que la familia era la base del orden tradicional y la garantía de la reproducción social ${ }^{39}$. Siguiendo los designios del Vaticano, Eza recomendaba incluso cierta participación del trabajador en los beneficios y la gestión de las empresas, lo que, en las circunstancias de aquel momento, no dejaba de resultar un sarcasmo. También abogaba por fomentar entre los obreros valores como el ahorro o la mora$\operatorname{lidad}^{40}$. Por último, no renunciaba al ideal de restaurar algún tipo de asociacionismo gremial, lamentando que no hubiera habido aún en la historia humana una edad en que «individuo, gremio y Estado» hubieran cabalgado al unísono, sin violencia ni terror ${ }^{41}$.

Por otra parte - como se mostrará luego - en política económica Eza fue partidario del nacionalismo económico, mientras en lo social se alineó con los planteamientos de su mentor Dato a los que ya se ha hecho alusión, que estaban plenamente en consonancia con las enseñanzas del catolicismo social y su denuncia del individualismo exacerbado. A las reformas laborales que favorecieran la armonía frente a la lucha de clases (paternalismo patronal protector, sindicatos mixtos y neo-gremialismo, mecanismos de arbitraje y posibilidad de jurados mixtos, etc.) había que acompañarlas de una adecuada base moral (defensa de la familia tradicional, del papel de la mujer como esposa y madre, de los valores cristianos básicos, etc. $)^{42}$.

En cuanto al papel subsidiario del Estado en la vida económica, el Vizconde pensaba que le correspondían las funciones de orientación,

38 Eza, 1943d, pp. 46-48.

39 En 1934 Eza impartió un curso sobre avances y retrocesos de la legislación social (Eza, 1934b). En él confirmaba lo expresado en textos anteriores: crisis de autoridad y confianza, retroceso de la libertad, materialismo y productivismo exacerbados, crítica a la democracia «formularia»y al parlamentarismo, etc. Véanse Eza, 1930; Eza, 1933.

${ }^{40} A B C, 9$ de febrero de 1934, pp. 35-36.

41 Eza, 1943d, p. 35.

42 Montero, 2004, pp. 124-128. Véase también Montero, 1999. 
coordinación y fiscalización, si bien respetando siempre rigurosamente la propiedad privada y los principios villaverdianos de nivelación presupuestaria y contención del gasto público, pues en ello le iba la vida al país ${ }^{43}$. Todo esto era acorde a sus elogios hacia la política financiera y el orden socio-político de Oliveira Salazar, a quien dedicó por completo el segundo de los folletos de Piedras miliarias. Lo político (1943). Elogios que contrastaban con el tono mordaz y ácido empleado en el cuarto folleto, Lo social (1943), dedicado a la actuación de socialistas y comunistas durante la Guerra Civil, y que en realidad era el mismo que había empleado siempre al referirse a Rusia y su revolución, a la que veía como una nueva edición - aumentada - de la francesa ${ }^{44}$.

En el ámbito estrictamente político, aun reconociendo la legitimidad histórica de la Constitución de 1876, Eza abogó por un sistema de representación corporativa, con la creación de una Asamblea que recogiese, interpretase y orientase - en armonía - todos los intereses y actividades, pues las clases debían valorarse por su funcionalidad y no eran antagónicas sino interdependientes ${ }^{45}$. En dicha Asamblea la representación económica sería sólo una rama integrante más, junto a otras que reflejaran valores históricos, culturales, científicos o morales. Su propuesta corporativa se manifestaba en una doble dimensión: a nivel profesional, como cauce económico de superación del conflicto de intereses, sin coerciones; y a nivel político, como cauce complementario de representación. Las corporaciones, integradas «por las uniones profesionales libremente abiertas a todo español, patrono u obrero, deseoso de ejercer un oficio», debían ser - siguiendo la doctrina social-católicaautónomas respecto al Estado, regulando las modalidades del salario y el trabajo, sosteniendo a los parados, y readaptándolos a la «economía nacional» ${ }^{46}$.

43 Eza, 1943d, p. 60.

44 En El enigma ruso y el ocaso socialista (1930), El ejemplo de Rusia, ¿un peligro o una lección? (1931), y La agonía del comunismo (1932), Eza mantuvo que el comunismo soviético se derrumbaría por inviabilidad económica.

45 Eza, 1943d, p. 53. Eza defendió la representación corporativa al menos desde $L a$ nueva democracia social (1918); continuó haciéndolo en multitud de textos, como La corporación como estructura nueva del Estado (1934). En La representación del país (1945), semanas antes de fallecer, se ratificó en la representación orgánica y propuso un sistema bicameral. Artola, 2016, pp. 121-122.

46 Eza, 1943d, pp. 50-53. 
Finalmente, hay que hacer referencia a la visión del Vizconde sobre el papel dirigente de las élites en la sociedad ${ }^{47}$. La democracia no era el gobierno del pueblo, sino el gobierno para el pueblo por los más capacitados, lo que venía a ser la quintaesencia del paternalismo clerical y nobiliario: «La democracia ha de consistir, no en que este pueblo en sus clases más ínfimas gobierne ni ejerza la hoy zarandeada soberanía nacional, sino en que cuente con clases altas capaces de dirigirle, educarle y gobernar para su bien ${ }^{48}$. Para Eza, había sido Balmes quien por primera vez había delimitado un concepto «acabado y nítido» de lo que debía constituir la función de la aristocracia, hablando de la selección aristocrática y de la aristocracia histórica del clero y la riqueza. Por su parte, el Vizconde proponía «la incorporación a los poderes legales o políticos [por vía de la representación corporativa] de aquellas fuerzas que con anterioridad [...][fueran] ya en el país poderes sociales» de facto $^{49}$. Ello se correspondía con la visión de la sociedad como un organismo vivo regido necesariamente por las leyes inmanentes de jerarquía, continuidad y herencia. Como el pensador catalán, Eza pensaba que el principio progresista de reducirlo todo al individuo representaba un desastre y amenazaba la vida de la sociedad; las clases altas tenían la obligación de ponerse al frente y adelantar sin demora las mejoras y reformas demandadas por el espíritu del siglo, entre ellas - y en primer lugar - las educativas: «Todas las clases civilizadoras serán clases altas, y todas las clases altas serán civilizadoras, o dejarán de ser altas» ${ }^{50}$.

\section{Un ejemplo relevante de la actividad como publicista: los consorcios industriales}

Eza desarrolló actuaciones destacadas como publicista en muy diversos ámbitos. Por ejemplo, en el terreno agrario, donde sus opiniones - como gran propietario y miembro de la Asociación de Agricultores de España - tuvieron un eco importante de forma continuada ${ }^{51}$. O en el terreno fiscal, donde sus artículos de 1927 en $A B C$ contra del impuesto so-

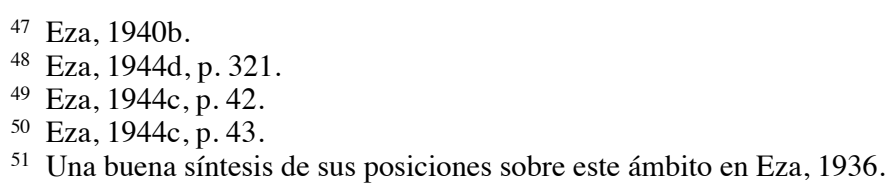


bre la renta de Calvo Sotelo influyeron en la movilización de las clases conservadoras para hacer fracasar el proyecto ${ }^{52}$. Sin embargo, aquí se ha elegido analizar su actuación como publicista en el terreno de la política industrial, pues hasta ahora no había sido abordada y enlaza con la cuestión fundamental del nacionalismo económico, que fue el rasgo definitorio de la economía española desde finales del siglo XIX.

El nacionalismo económico se basó en la implantación de medidas de política económica dirigidas a la protección y fomento de la actividad económica nacional ${ }^{53}$. Dentro esta vía Eza fue uno de los principales voceros o propagandistas de la idea de creación de consorcios industriales, asunto que planteó reiterada e intensamente a lo largo de la década de 1910 en múltiples artículos y obras como El problema económico de España (1916), La pasividad económica de España ante las futuras luchas económicas (1916), o Examen de un pseudo-plan económico (1917). Sin embargo, fue en su discurso de entrada en la Real Academia de Ciencias Morales y Políticas, La organización económica nacional (1919), donde quizá sintetizó mejor sus argumentos; de él ha dicho García Delgado que tuvo «un más que notable sentido de la oportunidad», al coincidir con la ola de corporativización en las economías europeas ${ }^{54}$. Posteriormente, durante la década de 1920 y comienzos de la de 1930, Eza continuó incidiendo en la cuestión de los consorcios industriales en textos de diversa naturaleza, pero ya cada vez con menor intensidad y menos explícitamente. Y de nuevo volvería sobre ella hacia 1940.

Se trataba de auspiciar la creación de agrupaciones de productores por ramas de actividad en las que estuviera representada de algún modo la Administración. Aunque el fin básico era regular el mercado fijando precios y cuotas de producción, también se perseguía promover mejoras que beneficiasen al conjunto del sector (infraestructuras de transporte y almacenamiento, recopilación de datos, etc.), crear nuevas capacidades (a través de escuelas profesionales para la formación de la mano de obra, grandes laboratorios compartidos para el desarrollo de nuevos productos y técnicas, etc.), o facilitar la importación de materias primas y maquinaria, la incorporación de las últimas innovaciones, o el acceso a la financiación (incluso mediante empréstitos públicos o garantizados). Todo ello debía

52 Eza llegó incluso a tildar la política fiscal de Calvo Sotelo de «despertador de la codicia de los de abajo», y de «socialismo mal digerido». Tomado de Robledo, 2010, p. 372.

${ }^{53}$ Fraile, 1999. San Román, 1999.

${ }^{54}$ García Delgado, 2002, pp. 12-13. 
combinarse, además, con un proteccionismo selectivo y una serie de auxilios y bonificaciones fiscales que mejorasen el potencial exportador ${ }^{55}$. El papel del Estado sería, por tanto, el de agente concertador de las energías individuales: se encargaría de organizar, orientar y estimular la industria ${ }^{56}$. Es decir, no se trataba de anular o sustituir a la iniciativa privada, sino de encauzarla, coordinarla y dirigirla, permitiendo así un desarrollo industrial vigoroso y con perspectivas de futuro ${ }^{57}$. Pero previamente, para poder «fundamentar» bien todas esas actuaciones públicas, era necesario elaborar «un inventario de la riqueza de España» ${ }^{58}$; esto es, había una labor de información estadística aún por realizar, con el fin de analizar las posibilidades comerciales y las necesidades y capacidades del país, e identificar los sectores objeto de atención.

Pero, ¿cuál era la razón de ser de los consorcios industriales? Al comienzo de la década de 1910, Eza consideró que, tras los necesarios saneamientos de la Hacienda Pública llevados a cabo por Silvela y Villaverde, convenía retomar y perfeccionar la senda proteccionista con impulso a la industria nacional que había marcado en su día Cánovas, y que parecía haberse difuminado desde 1907; los resultados - a su juicio - habían sido positivos, pero podían ser aún más favorables si se ponían en marcha los consorcios. En plena Gran Guerra, Eza llamó la atención sobre la precaria producción de muchos sectores industriales clave, incapaces de satisfacer las necesidades de la España de entonces y dependientes del extranjero en términos de innovación, personal técnico y bienes de equipo; al mismo tiempo, se refirió a la abundancia de capitales «inertes» en el contexto de neutralidad española que era preciso movilizar en favor del país ${ }^{59}$.

Y una vez terminado el conflicto mundial, Eza pasó a insistir en el fraccionamiento, disgregación y desorganización de la industria nacional, que junto a su pasividad y apatía habían hecho que desaprovechase la gran oportunidad representada por la neutralidad. Además, las renovadas rivalidades comerciales que se avecinaban con la llegada de la paz aconsejaban implementar una política industrial activa y bien diseñada, que permitiera alcanzar una escala de operaciones eficiente y aplicar las mo-

\footnotetext{
55 Eza, 1950, pp. 309-313, 325-332.

${ }^{56}$ Eza, 1950, pp. 274-276, 318.

57 Eza, 1919, p. 64.

58 Eza, 1950, p. 278.

59 Eza, 1950, pp. 285-288.
} 
dernas técnicas de producción en masa en sectores estratégicos (que para Eza parecían ser el minero, el metalúrgico y el químico) ${ }^{60}$. Por otra parte, había una tendencia clara: durante la guerra los gobiernos de las potencias contendientes ya habían ejercido un estrecho control de sus sectores industriales, y era previsible que - tras el armisticio - se mantuvieran de alguna manera los consorcios que habían funcionado razonablemente bien durante el periodo bélico (regulando el reparto de materias primas y mano de obra, fijando precios y cuotas de producción, etc. $)^{61}$.

Eza fue consciente de las críticas que despertaron los consorcios entre los economistas liberales, tales como supresión de la competencia, tendencia a la desaparición de la pequeña y mediana industria, pérdida de autonomía de los fabricantes particulares, burocratización de la gestión, o problemas de reparto - de materias primas, cuotas de producción, beneficios, etc. - entre los adheridos. Pero consideró que siempre que la intromisión del Estado no fuera excesiva, las ventajas de los consorcios compensaban con creces dichos inconvenientes: los intereses colectivos reclamaban la presencia nacional en sectores esenciales para el conjunto de la economía, que además estaban asociados a capacidades productivas que permitían disfrutar de verdadera independencia como país ${ }^{62}$. Por otro lado, sólo si se agrupaban y cooperaban las iniciativas particulares de una misma rama industrial, podrían ganar suficiente efectividad económica en un entorno internacional de creciente competencia ${ }^{63}$. Por último, la propia tecnología moderna imponía la necesidad de una escala de producción adecuada y una mayor especialización ${ }^{64}$.

En la práctica, sin embargo, los consorcios industriales no vieron la luz en los términos propugnados por Eza. Simplemente siguió habiendo grupos de presión de productores que empleaban sus organizaciones para obtener nuevas medidas protectoras. Así, a finales de los años veinte Eza se lamentaba de que se hubiera afianzado un proteccionismo industrial generalizado y sin criterio al servicio de intereses particulares, que por tanto carecía del deseable carácter estratégico y selectivo vinculado a los consorcios industriales que dictaba el interés general ${ }^{65}$.

\footnotetext{
60 Eza, 1919, pp. 74, 76-78.

${ }^{61}$ Eza, 1919, pp. 13-14.

62 Eza, 1919, pp. 14-15, 21-25.

63 Eza, 1919, pp. 19, 26, 63.

${ }^{64}$ Eza, 1919, p. 29.

65 Eza, 1950, p. 465.
} 


\section{Ejerciendo influencia directa: Eza y la deriva conservadora de la Asociación Española para el Progreso de las Ciencias}

En enero de 1908 se creó formalmente la Asociación Española para el Progreso de las Ciencias (AEPC), con lo que nuestro país se incorporaba al importante fenómeno asociativo vinculado a la ciencia que se había venido desarrollando en Europa desde el siglo $\mathrm{XIX}^{66}$. La idea parece que partió del Ateneo de Madrid, donde en ese momento se respiraba un ambiente científico propicio para este tipo de empresas. Para los pensadores progresistas, el atraso se debía, fundamentalmente, al aislamiento frente a las corrientes europeas del momento y la intolerancia religiosa. Con la citada Asociación se pretendía impulsar el conjunto de las ciencias positivas, siendo su principal actividad la organización de congresos científicos, concebidos como foro tanto de intercambio entre especialistas como de comunicación social. En diciembre de 1907 se había constituido el Comité ejecutivo de la Asociación, y días más tarde se designaron las Secciones correspondientes para organizar el primer Congreso a celebrar en Zaragoza el mismo año de 1908. Entre los vocales de dicho Comité figuraba el Vizconde, que a la sazón era Director de Agricultura, Industria y Comercio.

La AEPC surgió como una institución de carácter científico-general «fruto de ideas liberales y progresistas, cuyos principios se oponían frontalmente a las posiciones más tradicionalistas y conservadoras» ${ }^{67}$. Los fundadores de la Asociación (entre los que había un grupo bien definido formado por los miembros más avanzados de la Real Academia de Ciencias), identificaban el término Ciencia con el «estudio de la Naturaleza y de sus procedimientos, bien por medios experimentales, bien por la observación» ${ }^{68}$. Sin embargo, este espíritu positivista que la Academia de Ciencias había infundido inicialmente a la AEPC se iría apagando paulatinamente, a medida que sectores más conservadores provenientes de

66 Ausejo, 2008.

${ }^{67}$ García Sierra, 1993, p. 49. El exponente máximo de estas posiciones fue Menéndez Pelayo. Para él ciencia y fe eran perfectamente compatibles, pero no en un plano de igualdad: el progreso de la primera sólo era posible cuando armonizaba con el dogma (Santoveña, 1994, p. 27). En términos similares se expresó Eza (1944d): el método inductivo, como «herramienta de trabajo», le parecía útil, pero consideraba - siguiendo a Le Play y su «realismo católico»- que debía ajustarse siempre al ideal cristiano y no quedarse en mero materialismo.

${ }^{68}$ García Sierra, 1993, p. 49. 
la Academia de Ciencias Morales y Políticas (como Dato, Sanz Escartín, Eza, Zaragüeta, o Gascón y Marín, entre otros), se fueron haciendo con el control de la Asociación. Este último proceso culminó formalmente en 1928, cuando el Vizconde se hizo cargo de la presidencia tras el fallecimiento del catedrático de bioquímica José Rodríguez Carracido. Con anterioridad, Eza había ocupado desde 1919 el cargo de vicepresidente cuarto (con Dato de presidente), pasando a ser primer vicepresidente en 1922. Y ya como presidente permanecería en el cargo hasta su muerte, en 1945, tiempo más que suficiente para lograr consumar el giro orientativo al que se hará alusión a continuación. Además, le sucedería en el cargo su hombre de confianza, Gascón y Marín, de línea continuista.

Eza trasladó a los Congresos de la Asociación sus propias inquietudes como publicista y católico social, tratando en sus conferencias cuestiones candentes de actualidad, tales como el intervencionismo del Estado en materia social (Valencia, 1910), la organización democrático-social (Bilbao, 1919), la armonía entre lo político y lo económico (Salamanca, 1923), o la crisis del parlamentarismo (Coimbra, 1925). Pero el texto más relevante del Vizconde - por simbólico - fue su discurso inaugural del XI Congreso celebrado en Cádiz en 1927. Versó sobre «El alma nacional», y en él se ofrecían las claves para comprender el viraje observado en el seno de la Asociación, o lo que es lo mismo, la reorientación del desarrollo de la ciencia española hacia «el reencuentro con las verdades superiores y las esencias olvidadas del alma y genio nacionales» ${ }^{69}$. Comenzaba así una nueva etapa de la AEPC, caracterizada por el rechazo y abandono de las ideas positivistas que habían marcado la pauta general en la primera etapa. Esta nueva época se extendería hasta 1945, coincidiendo con el fallecimiento del Vizconde.

Eza también dejó constancia de sus propósitos en muchas otras ocasiones, fundamentalmente en las sesiones de apertura y clausura de los posteriores Congresos y en sus colaboraciones y recensiones de libros en Las Ciencias, la revista de la Asociación creada en 1934. En todas estas circunstancias dejó claro que los intereses de la AEPC habían cambiado radicalmente respecto a la etapa anterior. Ahora ya no tenía tanta importancia «exigir el desarrollo y cultivo de las ciencias positivas, ni la reforma de los planes de estudio para favorecer los estudios experimentales que [permitieran] alcanzar el desarrollo industrial propio de una nación

69 Eza, 1927. 
moderna»; simplemente bastaba con favorecer «el desarrollo de aquellos estudios encaminados a poner de manifiesto lo propio y característico del alma nacional, del espíritu del pueblo español, cuyos rasgos [aparecían] expresados en las obras filosóficas, teológicas y morales ${ }^{70}$.

No obstante, el citado discurso inaugural de 1927 fue la primera y mejor síntesis de lo que se proponía hacer Eza en los años posteriores. Lo estructuró en tres partes, dedicando la primera («El alma nacional en su brote y origen») y la segunda («Las características de nuestro pueblo y de la ciencia en él engendrada») a dilucidar lo que se debía entender por la «afirmación de la existencia en España de un alma nacional [cursiva en el original] que, al través de la Historia, nos ha unido como pueblo» ${ }^{71}$. Basándose en el «sin par Menéndez Pelayo», destacó como elementos conformadores de la unidad nacional el marco geográfico, la cultura romana, la lengua castellana y el catolicismo ${ }^{72}$. Así las cosas, la ciencia aparecía como expresión del alma nacional, debiendo la formación científica supeditarse, en todo momento, a la formación católica-moral, cimentada en los preceptos de la religión. Por último, dedicó la tercera parte a glosar el «deber de erección del monumento representativo del Alma Nacional». En particular, Eza planteaba la necesidad de continuar y rematar el inconcluso proyecto de una Historia de la filosofía española de Adolfo Bonilla, a quien sólo le había dado tiempo de escribir los dos primeros tomos de este estudio sobre la ciencia y la filosofía españolas para su replanteamiento en un sentido tradicional, de identidad nacional. En Bonilla el Vizconde veía la continuación del polígrafo santanderino, y por eso sugería a la AEPC que se implementasen los medios para continuar la citada obra. De esta forma, se contaría por fin con un inventario completo de «nuestra ciencia» que demostrase, con gran acopio de datos, su existencia. Y para que el plan no quedara en papel mojado, él mismo colaboraría con una oferta de mecenazgo: «lo hago [...] porque soy de los que creen que el frecuente uso de este vocablo [decadencia] no demuestra sino la afirmación contraria» ${ }^{73}$.

La caída de Monarquía y la proclamación la II República produjeron en el mundo conservador la percepción de que todo el orden social heredado se encontraba en peligro (la religión, la propiedad, la familia e in-

\footnotetext{
70 García Sierra, 1993, p. 66.

71 Eza, 1927, pp. 10-17.

72 Eza, 1927, pp. 10-19.

73 Eza, 1927, pp. 46-48.
} 
cluso la nación). En este contexto, Eza se reafirmaría aún más en su particular cruzada antipositivista contando con el apoyo entusiasta, entre otros católicos célebres, del clérigo neoescolástico J. Zaragüeta, formado en Lovaina con el cardenal Mercier. Por iniciativa suya se creó con carácter autónomo la Subsección de Filosofía, núcleo central en torno al cual se aglutinaba el resto de las disciplinas. Esta comenzó a funcionar ya en el XII Congreso de Barcelona (1929), el primero de la presidencia de Eza. Zaragüeta sería el presidente de dicha Subsección por mucho tiempo, y lo era aún en 1938 - en plena Guerra Civil - cuando, ausente Eza por estar aislado en el Madrid republicano, tuvo lugar en Santander el XV Congreso de la Asociación. Fue Zaragüeta quien pronunció el discurso inaugural de la joven subsección filosófica, titulado muy significativamente «Factores morales de nuestra reforma social». Y es que, para Zaragüeta, la futura reconstrucción nacional debía fundarse en una reforma moral, no científica. Esto es, la reforma científica tendría que supeditarse, en todo momento, a la formación moral asentada en los principios de la fe católica, en tanto que guía para poder alcanzar una noción global de la verdad. No se trataba ya de que la Asociación promoviera y favoreciera el cultivo de las ciencias positivas en beneficio de las nuevas generaciones, sino de limpiar la sociedad de «tanta maleza para hacerle recobrar, con su sentido nacional, la alta espiritualidad y el módulo de justicia que le [eran] propios» ${ }^{74}$.

Terminada la Guerra Civil, en plena exaltación de los ideales tradicionales, el Vizconde recuperó su protagonismo y en 1940 convocó el XVI Congreso de la AEPC en Zaragoza. Como presidente, y en su más que protocolaria alocución a la Virgen del Pilar, recordó que la Ciencia sin Dios sólo conducía a «catástrofes horrendas y a extravíos irremediables». Y en consonancia con tal postulado, definió a la Ciencia «como un medio y no un fin [...] para elevarnos a la belleza de la causa última de la existencia», y para robustecer «nuestra Religión» y honrar «nuestra Patria ${ }^{75}$. No en vano, Eza había pasado buena parte del conflicto bélico recluido en su domicilio de Madrid $^{76}$, imbuyéndose, según confesión pro-

74 García Sierra, 1993, p. 68.

75 García Sierra, 1993, p. 72.

76 El informe de la Brigada Miliciana de Investigación del 12 de diciembre de 1936 decía: «El ex vizconde [sic] está en su casa de Génova 13. Convendría hacer vigilancia para ver la manera de cogerle» (AHN, FC, Causa General 1797, Exp. 3, fol. 40). Según Campo (1968), Eza salvó la vida gracias a sus criados, pero no especifica más. 
pia, de «menendez-pelayismo» en su versión más radical - la del epílogo de la Historia de los heterodoxos españoles (del Menéndez Pelayo de veinte años) y la de la identificación entre el catolicismo y el ser español (viejo tópico del conservadurismo tradicional) - .

A dicho epílogo aludiría precisamente Eza en el discurso inaugural del citado congreso, titulado «Ciencia última: la Ética»: «¿Cómo - se preguntaba - restableceremos nuestros valores morales, superaremos la crisis espiritual actual y demostraremos que el hombre se conoce en su capacidad de progreso?». «Volviendo los ojos — respondía- a esa ciencia española de la que Menéndez Pelayo había realizado una catalogación, la única existente aún, donde el ilustre montañés demostraba lo que había escrito en el epílogo de los Heterodoxos», a saber, que España debía su unidad al cristianismo ${ }^{77}$. Luego Eza recordaba el consejo de Fichte, en sus Discursos a la nación alemana, sobre la obligación de «laborar por la Patria grande» sin escatimar medios. La suya era, como la de Menéndez Pelayo, una visión plenamente providencialista y cristiana, donde la historia era la expresión racional del orden teológico y sus leyes los dogmas cristianos sobre el hombre y su destino ${ }^{78}$. Por último, Eza terminaba negando los adelantos de la Ilustración, condenando la Revolución Francesa, y rechazando cualquier atisbo de entendimiento tanto con el marxismo como con el socialismo moderado o reformista, con el que antaño se había mostrado livianamente condescendiente.

El último congreso de la AEPC que presidió Eza fue el número XVIII, celebrado en Córdoba en 1944. Allí - una vez más - volvió a subrayar las mismas ideas en sus discursos inaugural y de clausura. En el primero apuntó: «es función muestra, evidentemente, la investigación científica», pero «cuidemos de que esta no nos ciegue hasta el punto de hacernos perder de vista que [...] la única ciencia ha de consistir en darnos cuenta del porqué de nuestra existencia y dedicar a ello nuestros actos y conducta, que es lo que hará viable, lo que hará real y efectiva esa verdad que describimos, que es del orden moral». Y en el discurso de clausura acababa aconsejando al auditorio la lectura del Radiomensaje de Pío XII, pues «todo lo que pudiéramos descubrir en la Ciencia está contenido en esa alocución ${ }^{79}$.

\footnotetext{
77 Eza, 1940a, pp. 60-64.

78 Novella, 2009.

79 Eza, 1944a, pp. 17-22, 60-63.
} 
En suma, Eza - asistido por Zaragüeta y García Morente - desarrolló en el seno de la AEPC una auténtica cruzada anti-positivista con el fin de reorientar la ciencia española hacia el «reencuentro con las verdades superiores y las esencias olvidadas del alma y el genio» ${ }^{80}$. Por tanto, la AEPC dirigida por Eza enlazaba perfectamente con lo que iba a ser la orientación científica del primer franquismo, a la que de algún modo preparó el camino. Como indicaba en 1940 el que fuera primer presidente del recién creado Consejo Superior de Investigaciones Científicas, José Ibáñez Martín, el Nuevo Estado pretendía «crear una ciencia española al servicio de los intereses espirituales y materiales de la nación», dentro de una «reestructuración tradicional de los valores universales de la cultura»; y ello exigía la depuración «implacable» de los «elementos nocivos» ${ }^{81}$.

\section{Conclusión}

El Vizconce de Eza fue un intelectual y político de segunda fila en la España del primer tercio del siglo XIX. Pero su figura merece atención por dos razones. Por un lado, como perfecto ejemplo de notable de la Restauración que aunaba capital, redes sociales, prestigio y poder, algo ya subrayado por distintos autores. Como ha señalado Carasa, fue gran propietario agrario con notable influencia provincial, parlamentario de largo recorrido - 1899-1923 - que llegó a ocupar varias carteras ministeriales, gestor de un prestigioso bufete, integrante del consejo de administración de importantes empresas, promotor de múltiples iniciativas de beneficencia y reforma social, y miembro destacado de asociaciones e instituciones civiles en ámbitos diversos (patronal, social, científico-educativo, etc.) ${ }^{82}$. En suma, aunque Eza fue un tradicionalista ortodoxo desde el punto de vista de su posicionamiento filosófico-teológico, en su praxis política fue «mestizo» rezagado, un hombre del sistema canovista de la Restauración, un aristócrata conservador acomodaticio, bien relacionado política y socialmente, con una inmejorable posición económica, y que ocupó innumerables cargos públicos.

Por otro lado, la figura de Eza es relevante como adalid y referente fundamental del conservadurismo católico, corriente con un peso signifi-

${ }^{80}$ Mainer, 2009, p. 273.
${ }^{81}$ Otero, 2001, p. 183.
${ }^{82}$ Carasa, 2001, p. 185. 
cativo en la España del primer tercio del siglo xx y a cuyos principios básicos se mantuvo esencialmente fiel a lo largo de su vida (aunque acentuando con el tiempo un tono cada vez más reaccionario). Dos aspectos - objeto de análisis en este trabajo - permiten considerarlo de este modo. En primer lugar, su ingente labor como publicista, que le llevó a convertirse en uno de los más activos del periodo, con presencia constante en todos los medios de difusión de la época (prensa, revistas, conferencias, congresos, debates, etc.). En particular, Eza puso al servicio de la divulgación y defensa de los principios del conservadurismo social-católico sus amplias inquietudes intelectuales - que incluían los ámbitos agrario, social, económico y político - y su continua preocupación por estar al corriente de las novedades bibliográficas, los problemas de actualidad y los acontecimientos internacionales. En algunos casos, como en el que se ha analizado aquí - a modo de ejemplo - sobre la promoción de los consorcios industriales, Eza llegó incluso a convertirse en una de las voces más destacadas del país a favor de esta particular estrategia del nacionalismo económico en boga.

En segundo lugar, Eza también intentó ejercer una influencia efectiva - desde las distintas instancias de poder que ocupó- con el fin de poner en práctica, en la medida de lo posible, los citados principios católicoconservadores. Buenas pruebas de ello se encuentran - por ejemplo- en los terrenos agrario y social, que se corresponden con los dos perfiles más estudiados del Vizconde. Pero aquí se ha optado por analizar un aspecto poco conocido y que muestra bien hasta donde llegó su voluntad de llevar a la práctica sus principios: el decisivo papel desempeñado por Eza desde 1927 en la reorientación «menéndez-pelayista» de la Asociación Española para el Progreso de las Ciencias, alejándola del positivismo inicial y truncando lo que podía haber sido una buena base de apoyo para el desarrollo científico español. Además, dicha reorientación señaló en cierto modo el camino a seguir para lo que luego sería la política científica del primer franquismo.

En definitiva, lo que conecta los dos aspectos del vizconde de Eza analizados en este trabajo es que constituyen las dos facetas que le conforman como gran adalid o referente del conservadurismo católico español del primer tercio del siglo XIX: la de gran publicista y la de influyente personaje público. Es decir, ambas facetas estaban al servicio de los principios del conservadurismo católico, buscando tanto su difusión entre la opinión pública, como su puesta en práctica en la medida de lo posible. 
El Vizconde de Eza, adalid del conservadurismo católico en el primer tercio del siglo XX

\section{Fuentes}

Archivo Histórico Nacional.

Archivo Histórico de la Fundación Antonio Maura. Fondos Antonio Maura y Gabriel Maura y Gamazo.

Real Academia de la Historia, Legado del Marqués de Montesa.

\section{Bibliografía}

ARTOLA, Miguel, «Los años sin rey. Imaginarios aristocráticos durante la segunda república y el primer franquismo (1931-1950)», Historia y Política, 35, 2016, pp. 103-127.

AUSEJO, Elena, «La Asociación Española para el Progreso de las Ciencias en el centenario de su creación», Revista Complutense de Educación, 19 (2), 2008, pp. 295-310.

BARCIELA, Carlos, «La colonización agraria en España durante el primer tercio del siglo XIX», en OLCINA, Jorge, y RICO, Antonio (eds.), Libro jubilar en homenaje al profesor Antonio Gil Olcina, Instituto de Geografía, Alicante, 2016, pp. 1043-1062.

BUENO, Gustavo, «Historia de la "Historia de la filosofía española"», Basilisco, 13,1992 , pp. 21-48.

CALAMA, Argimiro, «El Diputado soriano Vizconde de Eza, Don Luis Marichal y Monreal», Celtiberia, 77, 2003, pp. 249-360.

CALAMA, Argimiro, «El Diputado soriano Don Luis Marichal y Monreal», Celtiberia, 100, 2006, pp. 5-156.

CALVO, M. ${ }^{a}$ del Pilar, Defensa de intereses y cultura de la patronal castellanoleonesa (1876-1931), Tesis Doctoral, Universidad de Valladolid, 1999.

CAMPO, Francisco, «El Vizconde de Eza y la cooperación», Estudios Cooperativos, 16, 1968, pp. 27-40.

CARASA, Pedro (dir.), Élites castellanas de la Restauración, 2 vols., Junta de Castilla y León, Valladolid, 1997.

CARASA, Pedro, «Castilla y León», en VARELA, José (ed.), El poder y la influencia. Geografía del caciquismo en España (1875-1923), Marcial Pons, Madrid, 2001, pp. 175-236.

CUBEL, Antonio, y PALAFOX, Jorge, «El stock de capital de la economía española, 1900-1958», Revista de Historia Industrial, 12, 1997, pp. 113-146.

EZA, Vizconde de [Luis de Marichalar y Monreal], «Prólogo» a CHICOTE, César, La vivienda insalubre en Madrid, Madrid: Ayto. Madrid, 1914.

EZA, Vizconde de, El Problema económico de España, Imprenta B. Rodríguez, Madrid, 1916. 
EZA, Vizconde de, La organización económica nacional, Bernardo Rodríguez, Madrid, 1919.

EZA, Vizconde de, «Sesión de apertura del Congreso. Discurso inaugural», en Undécimo Congreso, celebrado en la ciudad de Cádiz, del 1 al 7 de mayo de 1927, vol. 1, Talleres Polig., Madrid, 1927, pp. 7-48.

EZA, Vizconde de, Ante el anuncio de reforma constitucional, Madrid, Ruiz Hermanos, Madrid, 1928.

EZA, Vizconde de, ¿Decadencia, senectud o crisis de crecimiento?, Ruiz Hermanos, Madrid, 1930.

EZA, Vizconde de, De mis carpetas. Una supuesta civilización nueva, Sobrinos de Minuesa, Madrid, 1933.

EZA, Vizconde de, De mis carpetas. Lo social y lo político, 3 vols., Sobrinos de Minuesa, Madrid, 1934a.

EZA, Vizconde de, El progreso social en suspenso, Sobrinos de Minuesa, Madrid, $1934 b$.

EZA, Vizconde de, La propiedad privada y sus deberes, Sobrinos de Minuesa, Madrid, 1934c.

EZA, Vizconde de, Agrarismo, C. Bermejo, Madrid, 1936.

EZA, Vizconde de, «La Ciencia última: la Ética», en Asociación Española para el Progreso de las Ciencias: XVI Congreso celebrado en Zaragoza durante los días 15 al 21 de diciembre de 1940. Discursos inaugurales del congreso $y$ de sus secciones y varios trabajos de éstas, Bermejo, Madrid, 1940a, pp. 43-69.

EZA, Vizconde de, Vivero de selectócratas, Bermejo, Madrid, $1940 \mathrm{~b}$.

EZA, Vizconde de, Piedras miliarias. Lo moral, Bermejo, Madrid, 1943a.

EZA, Vizconde de, Piedras miliarias. Lo político, Bermejo, Madrid, 1943b.

EZA, Vizconde de, Piedras miliarias. Lo social, Bermejo, Madrid, 1943c.

EZA, Vizconde de, Piedras miliarias. Bases constituyentes, Bermejo, Madrid, $1943 d$.

EZA, Vizconde de, «Sesión de clausura», en Asociación Española para el Progreso de las Ciencias: Discursos generales del Congreso y algunos trabajos de las secciones, Bermejo, Madrid, 1944a, pp. 60-66 y 80-87.

EZA, Vizconde de, «Conservador-Demócrata», en Asociación Española para el Progreso de las Ciencias: Discursos generales del Congreso y algunos trabajos de las secciones, Bermejo, Madrid, 1944b, pp. 320-342.

EZA, Vizconde de, «Mandar es servir», Revista Internacional de Sociología, 5 , 1944c, pp. 39-74.

EZA, Vizconde de, Sociología y Legislación, C. Bermejo, Madrid, 1944d.

EZA, Vizconde de, La representación del país, C. Bermejo, Madrid, 1945.

EZA, Vizconde de, Antología de las Obras del Excmo. Señor Vizconde de Eza, Escuela Social, Madrid, 1950. 
FRAILE, Pedro, «El pensamiento económico entre las dos repúblicas: del liberalismo a la formulación del autarquismo», en FUENTES QUINTANA, Enrique (coord.), Economía y Economistas Españoles, Vol. 6, Galaxia-Gutenberg, Barcelona, 1999, pp. 991-1012.

GARCÍA DELGADO, José Luis, La modernización económica en la España de Alfonso XIII, Espasa-Calpe, Madrid, 2002.I

GARCÍA SIERRA, Pelayo, «La evolución filosófica de la Asociación Española para el Progreso de las Ciencias», Basilisco, 15, 1993, pp. 49-81.

GLICK, Thomas F., «Ciencia, política y discurso civil en la España de Alfonso XIII», Espacio, Tiempo y Forma. Serie $\mathrm{V}, \mathrm{H}^{a}{ }^{a}$ Contemporánea, 6 , 1993, pp. 81-98.

GÓMEZ DÍEZ, Francisco J., «La monarquía frente al desafío revolucionario: Jaime Balmes», Mar Océana, 26, 2010, pp. 67-86.

GÓMEZ OCHOA, Fidel, El conservadurismo liberal y la Restauración: una explicación de las causas de la crisis del régimen liberal en España, Tesis Doctoral, Universidad de Cantabria, Santander, 1995.

GONZÁlEZ CALlEJA, Eduardo, La España de Primo de Rivera. La modernización autoritaria 1923-1930, Alianza, Madrid, 2005.

GONZÁLEZ CUEVAS, Pedro Carlos, El pensamiento político de la derecha española en el siglo XX: de la crisis de la Restauración al Estado de los partidos (1898-2000), Madrid, Tecnos, 2005.

GONZÁLEZ CUEVAS, Pedro, «La historia de las derechas a la luz del revisionismo histórico», Memoria y Civilización, 13, 2010, pp. 77-98.

GONZÁLEZ CUEVAS, Pedro, y MONTERO, Feliciano (2001): «Los conservadores españoles en el siglo XX», en MORALES, Antonio (ed.), Las claves de la España del siglo XX, vol. IV, Sociedad Estatal Nuevo Milenio, Madrid, 2001, pp. 39-62.

GONZÁLEZ HERNÁNDEZ, M. Jesús, «Un aspecto de la "revolución desde arriba": maurismo y acción social», Revista de la Facultad de Geografía e Historia, 1, 1987, pp. 145-161.

GONZÁLEZ HERNÁNDEZ, M. Jesús, «Moralización, intervención y eficacia nacional: los conservadores y la obra de modernizar España», Bulletin d'Histoire Contemporaine de l'Espagne, 44, 2010, pp. 117-146.

HUERTAS, Rafael, «Vivir y morir en Madrid: la vivienda como factor determinante del estado de salud de la población madrileña (1874-1923)», Asclepio, LIV (2), 2002, pp. 252-276.

MAINER, Juan, La forja de un campo profesional: pedagogía y didáctica de las ciencias sociales en España (1900-1970), CSIC, Madrid, 2009.

MONTERO, Feliciano, «La polémica sobre el intervencionismo y la primera legislación obrera en España, 1890-1900: El debate político parlamentario», Revista de Trabajo, 61-62, 1981, pp. 33-91. 
MONTERO, Feliciano, «Los católicos españoles y los orígenes de la política social», Studia Historica. Historia Contemporánea, n. ${ }^{\circ}$ 2, 1984, pp. 41-60.

MONTERO, Feliciano, «La crítica católica a la economía clásica y el primer catolicismo social», en FUENTES QUINTANA, Enrique (coord.), Economía y Economistas Españoles, Vol. 5, Galaxia-Gutenberg, Barcelona, 1999, pp. 451-493.

MONTERO, Feliciano, «Los católicos y la reforma social, 1890-1914», en PALACIO, J.I. (coord.), Reforma social en España, Consejo Económico Social, Madrid, 2004, pp. 99-128.

NOVELLA, Jorge, «Menéndez Pelayo y la polémica de la ciencia española», en Jornadas luso-espanholas de filosofía, 26-27 de noviembre de 2009, Academia Portuguesa da História, Lisboa, 2009, pp. 1-17.

OTERO, Luis E., «La destrucción de la ciencia en España. Las consecuencias del triunfo militar de la España franquista», Historia y Comunicación Social, 6 , 2001, pp. 149-186.

PANIAGUA, Ángel, «Space, rurality and power in Spain: the agrarian ideology of Vizconde de Eza (1873-1945)», Athens Journal of History, 5 (3), 2019, pp.169-188.

PAN-MONTOJO, Juan, «Introducción: Poderes privados y recursos públicos. Redes sociales, grupos de interés y políticas económicas, 1844-1975», Ayer, 66, 2007a, pp. 11-26.

PAN-MONTOJO, Juan, «La Asociación de Agricultores de España y la clase política, 1881-1942», Ayer, 66, 2007b, pp. 85-115.

PÉREZ SÁNCHEZ, Francisco, La protesta de un pueblo. Acción colectiva y organización obrera. Madrid, 1901-1923, Cinca, Madrid, 2005.

PERFECTO, Miguel A., «La derecha radical española y el pensamiento antiliberal francés en el primer tercio del siglo xx: de Charles Maurras a Georges Valois», Studia Historica. Historia Contemporánea, 30, 2012, pp. 47-94

PORTERO, Florentino, «El regeneracionismo conservador: el ideario político de Francisco Silvela», en TUSELL, J., MONTERO, F., y MARIN, J. M. (eds.), Las derechas en la España contemporánea, UNED/Anthropos, Madrid, 1997, pp. 45-58.

ROBLEDO, Ricardo, «La expropiación agraria en la Segunda República», en DE DIOS, Salustiano et al. (eds.), Historia de la propiedad: la expropiación, Universidad de Salamanca y Colegio de Registradores de la Propiedad, 2012, pp. 371-412.

RODRÍGUEZ JIMÉNEZ, José L., «¿Qué fue ser de derechas en España?: Conservadurismo liberal, derecha autoritaria, derecha franquista (y un epílogo)», Bulletin d'Histoire Contemporaine de l'Espagne, n. ${ }^{\circ} 44,2010$, pp. 21-58.

SAN ROMÁN, Elena, «Protección e intervencionismo en el primer tercio del siglo XX», en FUENTES QUINTANA, Enrique (coord.), Economía y Economistas Españoles, Vol. 6, Galaxia-Gutenberg, Barcelona, 1999, pp. 1023-1041. 
SANTOVEÑA, Antonio, Marcelino Menéndez Pelayo y las derechas en España, Ayto. Santander-Librería Estudio, Santander, 1994.

VELARDE, Juan, «La economía española de 1914 a 1931», en ANES, Gonzalo (ed.), Historia económica de España. Siglos XIX y XX, Real Academia de la Historia, Madrid, 1999, pp. 469-524.

\section{Datos de los autores:}

Tomás Martínez Vara (tomasmv@ccee.ucm.es) y José Luis Ramos Gorostiza son profesores vinculados al Departamento de Economía Aplicada, Estructura e Historia de la Universidad Complutense. Entre las líneas de investigación de Martínez Vara destaca principalmente la historia laboral ferroviaria, habiendo publicado en revistas como Revista de Historia Económica, Investigaciones de Historia Económica, Historia Agraria, Historia y Política, Historia Social, o Journal of Transport History. José Luis Ramos Gorostiza trabaja en historia de las ideas. Ha publicado en revistas como History of Political Economy, Journal of the History of Economic Thought, History of Economic Ideas, Revista de Historia Económica, Revista de Historia Industrial, o Historia Agraria. Ambos han trabajado y publicado sobre el catolicismo social en España. 